\title{
The Macrostructure Analysis of the Turbulent Mixing Boundary Layer Between Flows with the Same or Opposite Direction
}

\author{
Viktor Mileikovskyi' \\ Kyiv National University of Construction and Architecture, Povitroflotskyi pr., 31, Kyiv, 03680, Ukraine
}

\begin{abstract}
The approach to calculate large-scale vortexes boundary layer using approach of Professor A. Tkachuk is offered. It based on geometrical analysis of idealized macrostructure shown as a growing or constant radius vortex sheet. The small vortices in flows with a large-scale macrostructure plays secondary roles because they have incommensurably less energy than big vortices. They can be eliminated from consideration. We specify the velocity and temperature profile that differs from the jet boundary layer profile and better coincides with experiment. We find a growth law for a free boundary layer and length of currents cores. This approach help us to solve the actual task for energy efficient heating systems. We found the heat exchange coefficient between flows. It allows simulating the back flow effect in onepipe radiator nodes. The results of calculations coincides with well-known literature data.
\end{abstract}

Keywords: Turbulent boundary layer; vortex; current; jet; one-pipe heating.

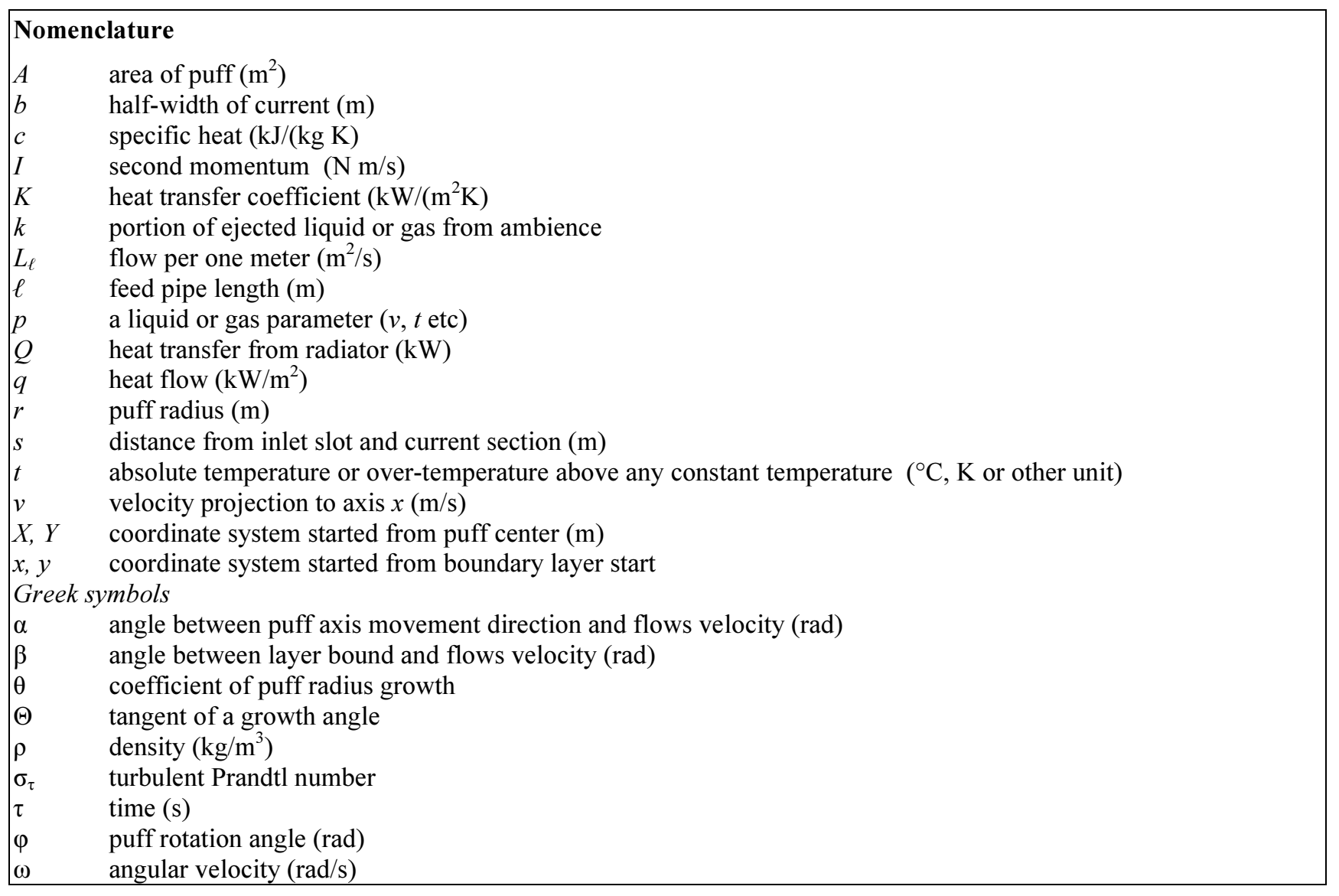

Corresponding author: Viktor Mileikovskyi. E-mail address: v_mil@ukr.net

http://dx.doi.org/10.3846/enviro.2014.273

(C) 2014 The Author. Published by VGTU Press. This is an open-access article distributed under the terms of the Creative Commons Attribution License, which permits unrestricted use, distribution, and reproduction in any medium, provided the original author and source are credited. 


\begin{tabular}{|ll|}
\hline Subscripts \\
$a$ & ambience \\
begin & current beginning part \\
$c$ & closing section of current \\
cold & cold heat carrier \\
core & current core \\
$e$ & ejected \\
hot & hot heat carrier at input to radiator node \\
$i$ & flow number -1 or 2 \\
$i p$ & interpuff layer \\
max & at opened thermostatic radiator valve (TRV) \\
$p$ & puff \\
$t$ & transit section of current \\
$x, y$ & projection to $x$ or $y$ axis \\
0 & puff center or inlet slot \\
1,2 & number of flow or number of puff \\
$1 \mathrm{a}, 1,1 "$ & related to line $1 \mathrm{a}, 1$ ', $1 "$ \\
\hline
\end{tabular}

\section{Turbulent Mixing Boundary Layers in HVAC Applications}

The well-known example of a turbulent mixing boundary layer in HVAC systems is a part of current at the beginning with uniform velocity profile in inlet hole. This part is formed by interaction of jet core and ambiance. Both flows have uniform profile (one flow can have zero velocity). The less studied example is a back flow effect of radiator nodes in one-pipe heating systems at closed TRVs on top feed pipes. The gravitational pressure cause forming of two flows in opposite directions at the top and bottom of the bottom feed pipe. Therefore, a radiator liable to back flow effect cannot be switched off decreasing energy efficiency of heating. The interaction of these flows cause intensive heat exchange that cannot be eliminated during back flow effect calculation.

The theory of flow interaction now is not so well developed to calculate both examples. H. Abramovich [1] try to use analogy between current and turbulent mixing boundary layer velocity and temperature profiles. The main problem of this approach is the boundary layer between equal velocities opposite flows. The jet boundary layer is asymmetric but the task has a symmetry. Where is the main flow? If we assume [1] "ping-pong" effect we can't answer the simple question: what velocity profile we may use at velocity difference $10 \%, 1 \%, 0.1 \%, 0.01 \%, 0.001 \% \ldots$ Experimental results [1] shows that velocity profile is closer to symmetrical than jet boundary layer. This theory was eliminated from the next issue [2] of this monograph. However, energy efficiency enforcement to heating coerce us to solve this task.

\section{The concepts of used approach}

The approach based on the theory developed by Professor of Kyiv National University of Construction and Architecture A. Tkachuk. Because of slow influence of viscosity (physical) in well-developed turbulent flow professor used ideal liquid laws. However, turbulent vortexes behave as foreign bodies (features). The forming of vortices is only appears to be random. Many authors try to search a regularity of forming the vortexes. A. Tkachuk [3] uses the known theorem: any flow in ambient immovable at infinity can be produced by a vortex sheet. So a boundary layer can be idealized as a vortex cord sheet rolled by the bounds of the layer. If the boundary layer size is small we can go without the scrupulous geometrical analysis of boundary layer and more precise describe the produced flow(s) using the theory of ideal liquid. However, if the boundary layer has large-scale vortexes the macrostructure geometry is the most important part of researches. This is a continuation of A. Tkachuk's researches. In most tasks (currents, hydro (aero)dynamic wakes behind bodies, turbulent mixing boundary layer) the characteristics of flow(s) are known and usually we assume uniform velocity and temperature profiles or rest (currents).

The first assumption is that the large-scale vortexes (puffs) has incomparably grater energy that a smaller vortexes so the lasts may be eliminated from consideration. We assume that the puffs roll as a hard wheel by the outer flows. The distance between puffs is comparable with the puffs diameter. Therefore, the puffs can be enlarged up to touch without the considerable precision drop. Nevertheless, we must take into consideration that the passage between puffs is small but present. The interpuff layer between puffs is not a dominant but usually it is important. There are different opinions about puffs growth mechanisms and solving the geometrical collisions during growth. One says that the vortexes grows by aggregation, another (I. Shepelev) [4] says that one of the colliding puffs is disintegrate to small vortexes and the puff growth mechanism is an ejection. The authors observed and filmed the second opinion (but it is not rule out that the first opinion was out of frame). We assume the growth by ejecting. Because additional disturbances tend to decay and the ejection is a result of pulsations or small vorticity we will guess minimal puff ejection to preserve the macrostructure.

The velocity and temperature profile can be averaged along the flow direction by the boundary layer part containing the half of puff. The growth during crossing some section may influence the result but this correction may not be important.

The main trouble that assumptions above says that the flow is neither steady nor quasi-steady. Therefore, the momentum equation requires corrections. This fact is theoretically and experimentally proved by W. Tolmien (different poles [1] of 
Tolmien source have no explanation), S. Butakov [5] etc. If the "unsteadity" is similar in two sections, it is not a problem for constant momentum law. The correction coefficient is the same in left and right equation parts. The description of the case of non-similarity or external forces now is in the final stage and will be published next time. In this work we try to use another approaches. We will careful writing the equations.

\section{The velocity and temperature profiles}

The chart of a free boundary layer (Fig. 1 a) shows a growing vortex sheet. Let us select a puff 1 with radius $r_{1}$. We accept the puff center $O_{1}$ as a coordinates begin. Axis $X$ shows the direction of flow 1 . This flow has greater or equal velocity $v_{1}$ than velocity flow 2. If the velocities are equal then the $X$-axis maybe aligned at the direction of any flow. Axis $Y$ goes from flow 2 to flow 1.

At some $Y$ value we build line sections $A B$ and $B C$ in the puff and interpuff layers. To calculate a profile we need to know target physical quantity $q$ distribution in puffs and interpuff layers.

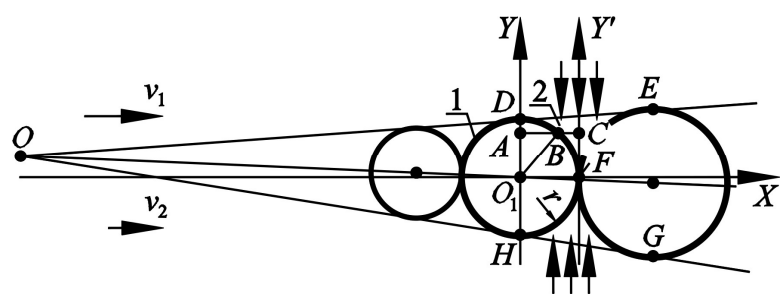

(a)

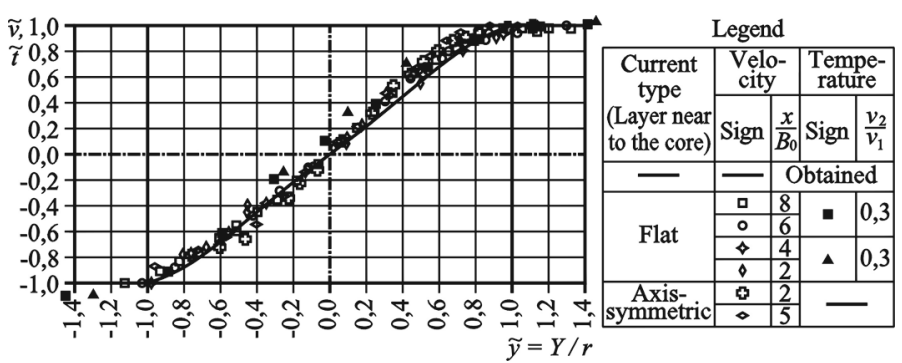

(b)

Fig. 1. Scheme (a) and results (b) of parameters profiles calculation: 1 - puff, 2 - interpuff layer

The common averaging formula for any quantity $q$ at any fixed value of $Y$ is $\tilde{p}_{x}=\left(\tilde{p}_{x, p}|A B|+\tilde{p}_{x, i p}|B C|\right) /|A C|$ where $\tilde{p}_{x, p}$ - an averaged parameter by the puff line section $A B,|A B|$ - length of the line section AB, $\tilde{p}_{x, i p}-$ an averaged parameter by the interpuff line section $B C,|B C|$ is a length of the line section $B C,|A C|$ is a length of the line section $A C$. Using Pythagorean Theorem for triangle $O_{1} A B$ we can use the equation:

$$
\tilde{p}_{x}=\tilde{p}_{x, p}\left(1-\left(Y / r_{1}\right)^{2}\right)^{1 / 2}+\tilde{p}_{x, i p}\left(1-\left(1-\left(Y / r_{1}\right)^{2}\right)^{1 / 2}\right) \text {. }
$$

A rolled (rotated \& translated) wheel (the idealized puff) has linear dependency of averaged $X$ velocity projection with known velocities at rolling points. The temperature distribution is a result of mixing the puff liquid (gas) with one ejected from corresponding flow. Therefore, at the bounds of the boundary layer the liquid (gas) is only ejected. Therefore, the temperature corresponds to flow temperatures. We accept the simplest distribution law - linear. In interpuff layers, there is only ejection of flows in the direction of $Y$. The $X$ projection of velocity and the temperature is equal to the corresponding flow velocity and the temperature:

$$
\tilde{p}_{x, p}=\frac{p_{1}+p_{2}}{2}+\left(Y / r_{1}\right) \frac{p_{1}-p_{2}}{2}, \quad \tilde{p}_{x, i p}=\frac{p_{1}+p_{2}}{2}+\operatorname{sgn}\left(Y / r_{1}\right) \frac{p_{1}-p_{2}}{2} .
$$

Using Eqns $(1,2)$ we obtain the following profiles of averaged parameters:

$$
\tilde{v}_{x}=\left(v_{x}-\frac{v_{1}+v_{2}}{2}\right) /\left(\frac{v_{1}-v_{2}}{2}\right)=\operatorname{sgn}\left(y / r_{1}\right)\left(1-|y / r|^{3 / 2}\right) ; \tilde{t}_{x}=\left(t_{x}-\frac{t_{1}+t_{2}}{2}\right) /\left(\frac{t_{1}-t_{2}}{2}\right)=\operatorname{sgn}\left(y / r_{1}\right)\left(1-|y / r|^{3 / 2}\right) .
$$

The averaged flow of $i$-th boundary layer part $L_{\ell, i}$ is an ejected flow $L_{\ell, e, i}$ from the beginning and maybe found integrating both halves of profile (3):

$$
L_{\ell, \mathrm{e}, i}=L_{\ell, i}=\left(0.8 v_{i}+0.2 v_{3-i}\right) r_{1} .
$$

This result (4) shows a fundamental difference with jet boundary layer at turbulent Prandtl number $\sigma_{\tau} \approx 0.7$ [6]: $\tilde{t}_{x}=\tilde{v}_{x}^{\sigma_{\tau}}$. However, this result corresponds to experimental data (Fig. $1 \mathrm{~b}$ ). There is no need to correct Eqns (3, 4) for opposite flows with the same velocity. 


\section{Development of boundary layer between co-current flows}

\subsection{Free turbulent mixing boundary layer}

The turbulent mixing boundary layer we may call "free" (Fig. 2 a) if both flows have no constrains. The layer can freely eject both flows. If one of the flows is constrained along the moving direction by the same one or a solid, this boundary layer may be called "semi-restricted". The boundary layer starts from zero width and behaves as a free one because its size is incompatibly smaller than distance to the restriction. During development it fills great part of the restricted flow and acts as semi-restricted. Experiments shows the linear bounds of the current core. Therefore, we can use the similar behavior of both layers as a boundary condition. If both flows are constrained along the moving direction, we call the boundary layer "restricted". This boundary layer starts as free, occupies most of flows and converts to restricted. The restricted layer cannot eject or develop. In this work, we will consider only free and semirestricted layers between flows with the same direction.

We need to include to consideration the next puff 2. We accept new Euclidean coordinate system $x, y$ started at the beginning $S$ of the boundary layer. Because both flows cannot be zero, $v_{1}>0$.

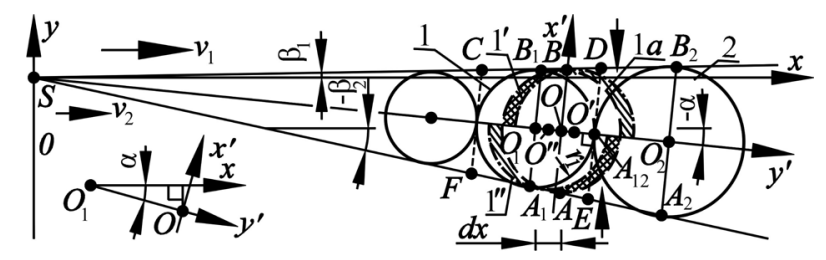

(a)

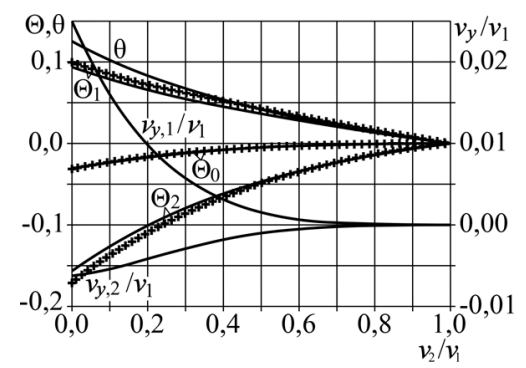

(b)

Fig. 2. Scheme (a) and results (b) of parameters profiles calculation: 1 - puff, 2 - interpuff layer, solid lines - results, $+-H$. Abramovich's theory [1]

The boundary layer expansion is linear. Let us build diameters $A_{1} B_{1}$ and $A_{2} B_{2}$ perpendicular to $O_{1} O_{2}$ through puff centers $O_{1}$ and $O_{2}$. Points $A_{1}$ and $A_{2}$ are in the flow 2. Puffs 1 and 2 touch point is $\mathrm{A}_{12} . \Delta B_{1} S O_{1}, \Delta \mathrm{B} 2 \mathrm{SO} 2$ and other same triangles are similar. Therefore, the puff radius $r$ grows linearly with coefficient of growth $\theta$ :

$$
r=\theta x .
$$

During time $d \tau$ the puff 1 goes and grows to circle la with radius $r$. Its center is a point $O$ with abscissa $x$. Points $A_{1}$ and $B_{1}$ moves to points $A$ and $B$. The direction of puff center motion we sign as $y^{\prime}$. Axis $x^{\prime}$ is perpendicular to $y^{\prime}$ through the point $O$, we direct from flow 2 to flow 1 . The angle between $x$ and $y^{\prime}$ is $\alpha$. It is positive if puffs axes move from flow 1 to flow 2 . However [1] most of the layers have negative $\alpha$, shown at Figure 2 a. If the puff rolls by flows the $x$ component of axis velocity is $\left(v_{1}+v_{2}\right) / 2$. During time $d \tau$ the puff center moves along $x$ by the distance $d x=\left(v_{1}+v_{2}\right) d \tau / 2$. Let us select a contour concentric to puff 1 with radius $r$. If both part of contours divided by axis $y^{\prime}$ will move along this axis with $x$ velocity components equal to corresponding flow velocities. Thus after the time $d \tau$ the parts moves to corresponding dashdot Figures 1' and 1" with centers O' and O". The centers movement distances along $x$ are the same: $\left(v_{1}-v_{2}\right) d \tau / 2$.

Both curvilinear triangles $A_{1} A_{12} A_{2}$ and $B_{1} A_{12} B_{2}$ are zones of ejection to puffs normally to $x$-axis. $x$-components of axes are $v_{1}$ and $v_{2}$. It is possible (for co-current flows) only if the layer consume at least all liquid (gas) of equivalent net hatched figures between circle la and arcs 1' i 1". Their areas $A_{1}=A_{2}$ maybe found by integration. Let us assume that the layer consumes less than these figures. In this case the puff 1 causes liquid (gas) movement along axis $x$ or the liquid (gas) leaves the boundary layer. The last case is applicable to opposite flows according the velocities. This difference is shown by experiments [1]. Also there is a great difference between this case and semi-restricted layers (or currents). In this case injection is possible from two sides. At the back of puff there are equigraphic zones hatched by parallel lines. These zones requires filling by ejected liquid or gas from embience (k-th portion) and net-hatched zone through a corridor at point $A_{12}$ (1-k-th portion). In semi-restricted layers or currents whole ejection performs from one side so these layers behave as at $k=1 / 2$. There is no behavior difference between free and semirestricted layer parts (for example at current core). Therefore, we may use this coefficient for free layers.

If puff radius $r_{1}$ grows linearly along $x$ and puff velocity is constant then there are the same order infinitesimals: $d \tau, d r_{1}$, $d y_{1}^{\prime}$ and $\left|O_{1} O_{1}^{\prime}\right|=d y_{1}=\left(v_{1}+v_{2}\right) d \tau /(2 \cos (\alpha))$.

The ejected liquid (gas) used to grow a part of the boundary layer containing the puff. It is a trapezium $C D E F$, $C F \| D E \perp y^{\prime}$. $C F$ and $D E$ - tangents to puffs in the touch points. $x$ and $x_{1}$ differs by infinitesimal. So we can exchange $x$ and $x_{1}$. The trapezium height and midsegment are the diameter of puff $2 r=2 \theta x$. The trapezium area is $A=4 \theta^{2} x^{2}$.

The balance equation per one meter of the boundary layer:

$$
d A=8 \theta^{2} x d x=k\left(d A_{1}+d A_{2}\right) .
$$

The Eqn (6) after areas integration, manipulations at $x>0$ and $x_{1}>0$ and substituting puff axis velocity in place of $d x_{1} / \mathrm{d} \tau$ : 


$$
\theta=\operatorname{tg}(\alpha)=\frac{k}{4 \cos (\alpha)} \frac{\left(1-\left(v_{2} / v_{1}\right)\right)}{\left(1+\left(v_{2} / v_{1}\right)\right)}=\frac{k}{4} \frac{1-\left(v_{2} / v_{1}\right)}{1+\left(v_{2} / v_{1}\right)}\left(1+\Theta_{0}^{2}\right)^{1 / 2}=\frac{1-\left(v_{2} / v_{1}\right)}{1+\left(v_{2} / v_{1}\right)}\left[\left(1+\Theta_{0}^{2}\right)^{1 / 2} / 8\right] .
$$

Using the Eqn (7) the relative ordinate of bounds at (at all formulas, top sign is for the flow 1, bottom sign -2):

$$
\frac{y_{i}}{x}=\Theta_{i}=\operatorname{tg}\left( \pm\left(0.5 \angle A_{1} S B_{1} \pm \alpha\right)\right)=\operatorname{tg}( \pm \operatorname{arctg}(\theta \cos (\alpha))+\alpha)=\frac{4 \Theta_{0} \pm k \frac{\left(1-\left(v_{2} / v_{1}\right)\right)}{\left(1+\left(v_{2} / v_{1}\right)\right)}}{\frac{4 \mp k\left(1-\left(v_{2} / v_{1}\right)\right)}{\left(1+\left(v_{2} / v_{1}\right)\right)} \Theta_{0}}=\frac{8 \Theta_{0} \pm \frac{\left(1-\left(v_{2} / v_{1}\right)\right)}{\left(1+\left(v_{2} / v_{1}\right)\right)}}{8 \mp \frac{\left(1-\left(v_{2} / v_{1}\right)\right)}{\left(1+\left(v_{2} / v_{1}\right)\right)} \Theta_{0}} \text {. }
$$

The ejection (4) performs along the $x$ axis (with velocity $v_{i}$ and relative flow) and along the $y$ axis (using the Eqns $(4,5,7)$ :

$$
\begin{gathered}
L_{\ell, e, x, i} /\left(v_{1} x\right)=v_{i} y_{i} /\left(v_{1} x\right)=v_{i} \Theta_{i} / v_{1} \\
\frac{L_{\ell, e, y, i}}{v_{1} x}=\frac{1}{8} \frac{1-\left(v_{2} / v_{1}\right)}{1+\left(v_{2} / v_{1}\right)}\left(1+\Theta_{0}^{2}\right)^{1 / 2}\left(0,8\left(v_{i} / v_{1}\right)+0,2\left(v_{3-i} / v_{1}\right)\right)=\frac{L_{\ell, e, i}-L_{\ell, e, x, i}}{v_{1} x}= \pm\left(\left(v_{i} / v_{1}\right) \Theta_{i}-\left(v_{y, i} / v_{1}\right)\right) .
\end{gathered}
$$

Using the Eqns (7-10) the relative ejection velocities:

$$
\frac{v_{e, x, i}}{v_{1}}=\frac{v_{i}}{v_{1}} ; \quad \frac{v_{e, y, i}}{v_{1}}=\frac{v_{i}}{v_{1}} \frac{4 \Theta_{0} \pm k \frac{1-\left(v_{2} / v_{1}\right)}{1+\left(v_{2} / v_{1}\right)}}{4 \mp k \frac{1-\left(v_{2} / v_{1}\right)}{1+\left(v_{2} / v_{1}\right)} \Theta_{0}} \mp 0,05\left(4 \frac{v_{i}}{v_{1}}+\frac{v_{3-i}}{v_{1}}\right) k \frac{1-\left(v_{2} / v_{1}\right)}{1+\left(v_{2} / v_{1}\right)}\left(1+\Theta_{0}^{2}\right)^{1 / 2} .
$$

The momentum equation in projections to the axis $y$ is $I_{y, 1}+I_{y, 2}=\rho_{1} v_{y, 1} L_{\ell, e, 1}+\rho_{2} v_{y, 2} L_{\ell, e, 2}=0$. Using Eqn (11) at $v_{2} \neq v_{1}$ we obtain:

$$
\left(v_{e, y, 1} / v_{1}\right)\left(4+\left(v_{2} / v_{1}\right)\right)+\left(\rho_{2} / \rho_{1}\right)\left(v_{e, y, 2} / v_{1}\right)\left(4\left(v_{2} / v_{1}\right)+1\right)=0 .
$$

To calculate $\Theta_{0}$ we may numerically solve the lengthy equation obtained using Eqn (12) with formulas (11) at $k=1 / 2$. To find other parameters (Fig. 2 b) we use the formulas $(4,7-11)$. The results have good congruence with theoretical data of $\mathrm{H}$ Abramovich and k- $\varepsilon$ modeling.

For the semi-restricted boundary layer, we may eliminate $A_{2}$ from equations. It is equal to use the Eqn (6) and $k=1 / 2$. Therefore, the formulas (1-11) are useful. However, we cannot use the Eqn (12) because it do not take into consideration a reaction power of the restriction. We can include the reaction but we need to know at least the Bussinesk coefficient. Therefore, if it is possible we may replace the Eqn (12) by another one.

\subsection{Semi-restricted turbulent mixing boundary layer. The flat current beginning part}

As it is written before, the growth equations may be obtained eliminating $A_{2}$ from the Eqn (6) that is equivalent using $k=1 / 2$ in the Eqns (6-11). Additional equations may describe the restriction influence. For a free flat current (Fig. 3 a) all of the inlet flow may be consumed by two boundary layers until they touch.

The flat free current has uniform velocity $u_{0}$ profile in inlet slot $M N$ (with width $2 b_{0}$ ). This profile continues in a core of equivalent velocities $M Q N$. The core interacts with ambiance moved with velocity $u_{a}$ creating the turbulent mixing boundary layers $M R Q$ and $N Q T$. What flow is the flow 1 or 2 is dependent on velocity values. Axis $s$ is the current axis in the direction of the inlet flow started from the center $K$ of inlet slot $M N$. So $x=s, v_{1}=\max \left(u_{a}, u_{0}\right)$ and $v_{2}=\min \left(u_{a}, u_{0}\right)$. The factor in square brackets of the Eqn (7) is coincident with a data [1] $(0,2 \ldots 0,3)$. This range is for angles $\alpha<33^{\circ} 33^{\prime}$. The inlet flow is $L_{\ell, 0}=2 u_{0} b_{0}$. At the distance $s_{c}$ the internal bounds of layers closes at point $Q$ in closing section $R T$. The part of current before closing section can be called "closing part". These two boundary layers may consume $\left(L_{\ell, e, c o r e}\right.$ for each one) all inlet flow $L_{\ell, 0}: 2 L_{\ell, e, c o r e}=L_{\ell, 0}$. Using the formula (4) replacing the velocities $v$ by $u$ and the abscissas $x$ by $s_{c}$ we obtain:

$$
s_{c} / b_{0}=40\left|\left(1+\left(u_{a} / u_{0}\right)\right) /\left(1-\left(u_{a} / u_{0}\right)\right)\right|\left(1+\Theta_{0}^{2}\right)^{-1 / 2} /\left(4+\left(u_{a} / u_{0}\right)\right) \approx 40\left|\left(1+\left(u_{a} / u_{0}\right)\right) /\left(1-\left(u_{a} / u_{0}\right)\right)\right| /\left(4+\left(u_{a} / u_{0}\right)\right) .
$$

From $\triangle U M V$ we can find the angle $\alpha$ because $|\angle U M V|=|\alpha|$ :

$$
\left|\Theta_{0}\right|=\operatorname{tg}(\angle U M V)=|U V| /|M U|=(|Q V|-|Q U|) /|M U|=\theta-\left(b_{0} / s_{c}\right) .
$$

Solving Eqns $(7,13,14)$ gives error of approximate part of Eqn (13) no greater than $0.1 \%$ up to $u_{a} / u_{0} \leq 4.45$. But if the velocity of ambiance $u_{a}$ is too greater than starting velocity $u_{0}$ the flow is near to trail behind a body with circulating zones. In this case, the equations give high error greater than $5 \%$. The tangent of start part growth:

$$
\Theta_{\text {begin }}=\left(2 r_{c}-b_{0}\right) / s_{c}=2 \theta-\left(b_{0} / s_{c}\right) \approx 0.025\left|\left(1-\left(u_{a} / u_{0}\right)\right) /\left(1+\left(u_{a} / u_{0}\right)\right)\right|\left(6-\left(u_{a} / u_{0}\right)\right) .
$$


where $r_{c-}$ is the puff radius in the closing section. When $u_{a} / u_{0}=6 \Theta_{\text {begin }}=0$. This impossible result said that the vacuum and back flows in the trail are breaking the equations. We limit the range $u_{a} / u_{0} \leq 3$ because of the great deviation.

After closing, the boundary layers are developing in the same direction and linear growth. This development cause immersing of one layer to another. This process continues until the puffs will set into chessboard order [7] in transition section $W X$ at $s=s_{t}$. The final depth of immersing $|Y Z|=0.069|W Y|$ [7]. The half-width of this section is:

$$
|\mathrm{WY}|=b_{t}=b_{0}+\Theta_{\text {begin }} s_{t} \text {. }
$$

Using Eqns $(3,7,15,16)$ taking into account that $|\mathrm{WZ}|=2 r_{t}=2 \theta s_{t}$ we can write:

$$
s_{t} / b_{0}=\left(s_{c} / b_{0}\right) \frac{4+\left(u_{a} / u_{0}\right)}{3.3545+\left(u_{a} / u_{0}\right)} \approx \frac{40}{3.3545+\left(u_{a} / u_{0}\right)}\left|\frac{1+\left(u_{\mathrm{a}} / u_{0}\right)}{1-\left(u_{a} / u_{0}\right)}\right| .
$$

The half-width of transit and closing sections is:

$$
b_{t} / b_{0}=\left(s_{t} / b_{0}\right) \Theta_{\text {begin }} \approx 1 /\left(0.3586+0.1069\left(u_{a} / u_{0}\right)\right) ; b_{c} / b_{0}=\left(s_{t} / b_{0}\right) \Theta_{\text {begin }} \approx\left(6-\left(u_{a} / u_{0}\right)\right) /\left(4+\left(u_{a} / u_{0}\right)\right)
$$

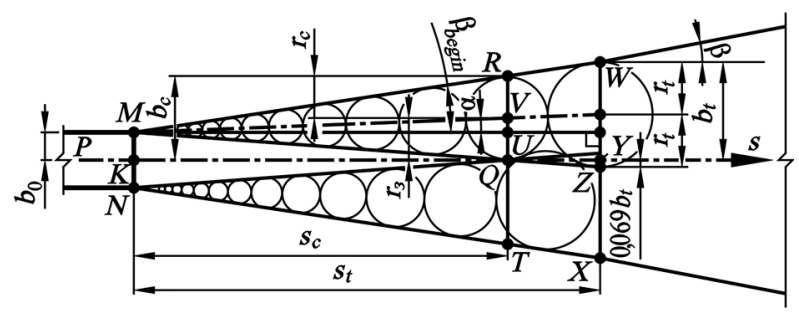

(a)

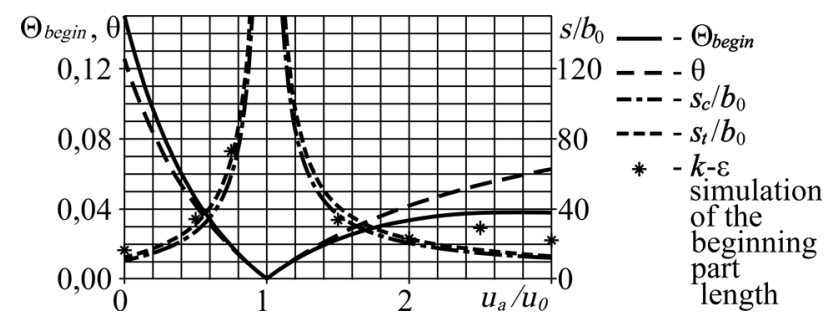

(b)

Fig. 3. Scheme (a) and results (b) of calculations

The results of calculation by the Eqns $(7,15,17,18)$ at $\rho_{1} \approx \rho_{2}$ are on the Fig. $3 \mathrm{~b}$. The following comparison shows good coincidence with known theoretical and experimental data for free currents in the still ambiance:

- $\theta=0.125$. By H.N. Abramovich [1] $\theta=0.27 / 2=0.135$. The discrepancy is $7.4 \%$ );

- Obegin $=0.15$. By H.N. Abramovich [1] @begin $=(2.4-1) / 9=0.156$. The discrepancy is 3,85\%;

- $\mathrm{sc} / \mathrm{b} 0=10 ; \mathrm{st} / \mathrm{b} 0=11.92$. By Fig. 2.8 [1] we have 9.9...12.1. By the H. Abramovich's theory, we have a value 9. By

V.N. Taliev [8] - 14.4. Our data lays between the well-known data;

- $\mathrm{bt} / \mathrm{b} 0=2.789$. By H.N. Abramovich [2] bt $/ \mathrm{b} 0=1 / 0.416=2.4$. By V.N. Taliev [8] bt $/ \mathrm{b} 0=3.16$. Our data lays between the well-known data.

\section{Heat transfer through restricted and growing boundary layers}

One of the energy-efficiency problems of renovated one-pipe heating system is a back flow effect. When top feed pipe is closed by TRV the flow runs to radiator by the top part of bottom feed pipe, cools in the radiator and returns to the riser by the bottom part of this feed pipe (Fig. 4 a). This effect decreases the energy efficiency and comfort level at great heat inputs or at temperature chart cut. A room has no heat needs but its radiator cannot be switched off. The consumer must pay for unnecessary heat, must breeze the pollutants ejected during this unnecessary heat generation and must feel overheating. To simulate the back flow effect [9] we need to know a heat transfer coefficient between flows. The heat transfer is one of the main factors throttling back flow by hot heat carrier cooling.

The mixing boundary layer maybe idealized as a large-scale vortex (puff) cord sheet. The flow division surface maybe accepted as a flat containing puff axis. Let us select a puff with radius $r$. The angular velocity of axial rotation is $\omega=\left(v_{1}+v_{2}\right) /(2 r)$. During time $\tau$ the vortex rotates for angle $\varphi=\omega \tau=\left(v_{1}+v_{2}\right) \tau /(2 r)$. The puff volume per one meter of depth $W=\varphi r^{2} / 2=\omega \tau=\left(v_{1}+v_{2}\right) \tau r / 4$ crosses the flow division surface. Because of intensive mass exchange of the puff, the temperature of a particle crossing flow division surface is near to the temperature of flow, which the particle leaves. The vortex acts as a regenerative drum heat exchanger. The mass flow and the averaged velocity by the flow division surface of the cross-flow from the flow $i$ to the flow $j=3-i$ are:

$$
G_{i, j}=\rho_{i} W / \tau=\rho_{i} \varphi r^{2} /(2 \tau)=\rho_{i} \omega r^{2} /(2 \tau)=\rho_{i}\left(v_{1}+v_{2}\right) r / 4 ; \quad v_{i j}=G_{i j} /\left(2 r \rho_{i}\right)=\left(v_{1}+v_{2}\right) / 8 .
$$

The averaged heat flow transferred with the puff through one area unit of the flow division surface is:

$$
q=\bar{c} \rho v_{i j}\left(t_{\text {hot }}-t_{\text {cold }}\right)=\bar{c} \rho\left(v_{1}+v_{2}\right)\left(t_{\text {hot }}-t_{\text {cold }}\right) / 8=K\left(t_{\text {hot }}-t_{c o l d}\right),
$$

where $\overline{c \rho}=\left(c_{1} \rho_{1}+c_{2} \rho_{2}\right) / 2$ - average volumetric heat capacity or product of specific heat $c_{i}$ and density $\rho$, $t_{\text {hot }}=\max \left(t_{1}, t_{2}\right)$ and $t_{\text {cold }}=\min \left(t_{1}, t_{2}\right)-$ the temperature of the hot and cold media; $K$ - heat transfer coefficient that maybe found from Eqn (20): 


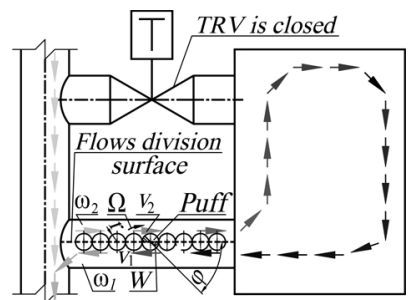

(a)

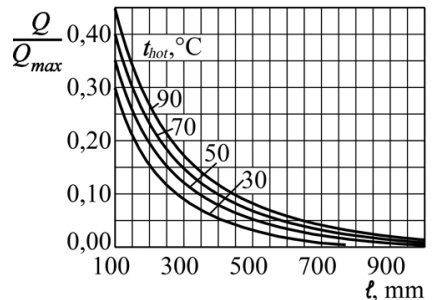

(b)

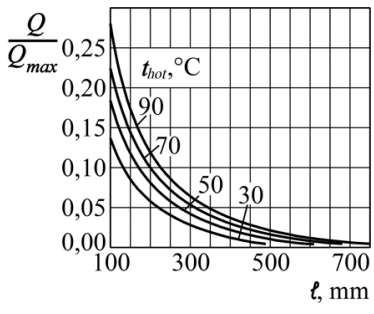

(c)

Fig. 4. The back flow effect: (a) scheme, (b) heat transfer $Q$ related to the maximal heat transfer $Q_{\max }$ (at opened TRVs) for the feed pipe diameter $d_{n}=15 \mathrm{~mm}$ and (c) $\mathrm{d}_{n}=20 \mathrm{~mm}$ at different feed pipe length $\ell$ and hot heat carrier temperatures $t_{\text {hot }}$.

$$
K=\bar{c} \rho\left(v_{1}+v_{2}\right) / 8
$$

In the Eqns (26-27) we can replace $\bar{c} \rho$ by $\bar{c} \bar{\rho}$ only if the heat capacity (or density) has small deviation at temperature change. The Eqn (26) shows independence of the averaged velocity on the puff radius (boundary layer half-width) and the density of flows.

Because the radius in the Eqn (25) plays the role of the length not a width both Eqns (25) and (26) are independent on the width. So these equations are accepted for growing boundary layer.

Using the formula (28) the back flow simulation application was created using standard engineering method for pressure, heat losses and natural (gravitation) circulation pressure calculation. The heat transfer $\mathrm{Q}$ related to heat transfer $Q_{\max }$ at opened TRV for radiator node with M140 radiators calculation (Fig. 4 b, c) are shown and it is corresponds to experiments. In the past manual valves have been installed at lower feed pipes to fully eliminate the effect. There are too few experimental data because this effect occurs only in thermal modernized one-pipe systems equipped with TRVs at top feed pipes.

Approximation formula for residue heat transfer published in [9]. It allows to analyze back flow effect. If the residue heat transfer is unallowable we need to enlarge feed pipes, replace radiator by lower one or install back flow restrictor. If the transfer is allowable we don't need to increase lower feed pipe resistance. It is not a good idea to increase pressure drop in feed pipe without requirement because it decreases TRV authority and efficiency of thermal control.

\section{Conclusions}

- We offer the approach to calculate large-scale vortexes boundary layer using approach of prof. A. Tkachuk. This approach based on geometrical analysis of idealized macrostructure shown as a growing or constant radius vortex sheet. This approach allows obtaining velocity and temperature profiles in mixing turbulent boundary layer. This profile describes boundary layer between opposite flows with equal velocities as well as other cases. It coincides with experimental data. Also we calculate growth low of boundary layer and beginning part of free current.

- We found heat exchange coefficient between flows. It allows simulating the back flow effect in one-pipe radiator nodes. We can calculate residual heat transfer of radiators. If it is unallowable we need to restrict back flow. If it is allowable we can eliminate unnecessary back flow restrictor.

\section{References}

[1] Абрамович, Г. Н. 1960. Теория турбулентных струй [The turbulent currents theory]. Москва: Государственное издательство физикоматематической литературы [State physics and mathematics literature press]. $715 \mathrm{~S}$.

[2] Абрамович, Г. Н.; Гиршович, Т. А.; Крашенинников, С. Ю. 1984. Теория турбулентных струй [The turbulent currents theory]. Москва: Наука [Science]. $716 \mathrm{~S}$

[3] Ткачук, А. Я.; Зайченко, Е. С.; Потапов, В. А.; Цепелев, А. П. 1985. Системы отопления. Проектирование и эксплуатация [Неаting systems. Design and operation]. Киев: Будівельник [Builder]. $136 \mathrm{~S}$.

[4] Шепелев, И. А. 1978. Аэродинамика воздуиных потоков в помещении. [Aerodynamics of air flows in premises] Москва: Стройиздат [Вuilding press], 1978. $144 \mathrm{~S}$

[5] Бутаков, С. Е. 1965. О количестве движения и методе расчёта изотермических струй [About the momentum and calculation method of isothermal currents], в Теория и расчёт вентиляционных струй (сборник трудов) [in Theory and calculation of ventilation curents]. Ленинград: Ленинградское правление научно-технического общества строительной индустрии СССР, Всесоюзный научно-исследовательский институт охраны труда в г. Ленинграде [The Leningrade head of scientific and technical community of USSR building industry, All-USSR scientific research institute of labour protection in Leningrade], 81-95.

[6] Гримитлин, М. И. 1982. Распределение воздуха в помещениях [Air distribution in premises]. Mосква: Стройиздат [Building press]. 164 S

[7] Милейковский, В. О. 2009. Геометричне моделювання вільних ізотермічних струмин [The geometrical modeling of free isothermal currents], y Міжвідомчий науково-технічний збірник «Прикладна геометрія та інженерна графіка» [in interagengy scientific and technical digest “Applied geometry and engineering graphic"]. Вun. 82. Київ: КНУБА [КNUCA], 190-196.

[8] Талиев, В. Н. 1979. Аэродинамика вентиляиии: учеб. пособие для ВУЗов [Aerodynamic of ventilation. Teaching aid for high school]. Mосква: Стройиздат [Building press]. $295 \mathrm{~S} .111$

[9] Милейковский, В. 2013. Математическое моделирование остаточной теплопередачи отопительных приборов однотрубных вертикальных систем отопления [The mathematical modeling of radiators residue heat transfer in one-pipe vertical heating systems], Danfoss Info (3-4): 20-23. 